\title{
UM CADERNO, UMA TESE E ALGUMAS HISTÓRIAS SOBRE O ENSINO ACADÊMICO DE HISTÓRIA ${ }^{1}$
}

\section{A NOTEBOOK, A THESIS AND SOME STORIES ABOUT THE TEACHING ACADEMIC OF HISTORY}

João Paulo Gama Oliveira²

\begin{abstract}
RESUMO: O presente estudo tem por objetivo investigar o ensino acadêmico de História por meio das aulas ministradas por Gonçalo Rollemberg no período de 1951 a 1962, recorte cronológico referente ao funcionamento do curso de Geografia e História de forma conjunta, procurando descortinar a relação entre a concepção de História do aludido professor e a sua prática de ensino. Para atingir tal fim usaremos como fontes principalmente o caderno de uma ex-aluna do curso e uma tese data de 1938, além de depoimentos orais de ex-alunos. Por meio da análise concluímos que vários elementos do entendimento de Gonçalo Rollemberg Leite acerca de conteúdos da História esboçados na sua tese escrita para um concurso na cobiçada congregação do Atheneu Sergipense se fizeram presentes na sua prática de ensino nas salas de aula da Faculdade católica sergipana.
\end{abstract}

Palavras-chave: Ensino Acadêmico de História. História do Ensino Superior. Faculdade de Filosofia. História das Disciplinas.

ABSTRACT: The present study aims to investigate the academic teaching of History through classes taught by Gonçalo Rollemberg from 1951 to 1962, chronological for the clipping operation of the course of Geography and History together, trying to uncover the relationship between the design of the History alluded to teacher and their practice of teaching. To achieve such order we will use as sources especially the notebook of an ex student of the course and date thesis of 1938, in addition to oral testimonials from former students. Through analysis we concluded that several elements of the understanding of Gonçalo Rollemberg Leite about contents of History outlined in his thesis written for a contest in the coveted congregation of Atheneu Sergipense were present in their teaching practice in classrooms of the Faculdade Católica of Sergipe.

Keywords: Academic Teaching of History. History of higher education. Faculdade de Filosofia. History of disciplines.

${ }^{1}$ O presente estudo consiste em parte da dissertação defendida no Programa de Pós-Graduação em Educação da Universidade Federal de Sergipe, desenvolvida com Bolsa CAPES. Para outras informações consultar Oliveira (2011).

2 Doutorando em Educação pela Universidade Federal de Sergipe e Professor da Faculdade Atlântico. 


\section{Introdução}

Em meados do século XX Gonçalo Rollemberg Leite ${ }^{3}$ era o docente que lecionava as três disciplinas de História da Civilização no curso de Geografia e História da Faculdade Católica de Filosofia de Sergipe (FCFS). A atuação do Professor Gonçalo é ainda pouco conhecida embora com alguns estudos na área do Direito, pouco sabemos do seu trabalho no universo da História. Nesse sentido, buscamos no presente estudo discutir aspectos do ensino de História da Civilização na FCFS, ministrada por Gonçalo Rollemberg, a partir principalmente de duas fontes, uma tese e um caderno.

A tentativa é de fazer um contraponto entre os aspectos teóricos da História na tese com o caderno e os depoimentos dos seus alunos na busca de conhecer elementos da sua prática de ensino. O caderno (s/d) pertence à Maria Lígia Madureira Pina e a tese foi apresentada pelo jurista no concurso para catedrático de História da Civilização no Atheneu Sergipense no ano de 1938, intitulada de Aspectos Econômicos da Idade Média.

Assim, almejou-se construir "uma aproximação, até onde for possível, às práticas escolares e à realidade em classe através de memórias, informes, exames, diários e cadernos de aula, documentos particulares etc." (VIÑAO, 2008a, p. 199). Essa relação é considerada pelo autor como um dos principais aspectos no estudo da história de uma disciplina.

Levando em consideração também as "[...] indubitáveis vantagens que os cadernos escolares oferecem - em comparação com as prescrições oficiais, os livros textos e os programas [...]" (VIÑAO, 2008b, p. 25), mas sem cair na tentação de pensar que o caderno escolar reflete toda a atividade do ambiente educacional, sabemos que nem tudo está no caderno, e além do mais nunca reconstruiremos o passado como efetivamente aconteceu, pois, como nos ensina Michel de Certeau (2008, p. 19), o historiador "Não faz a história, pode apenas

\footnotetext{
${ }^{3}$ Gonçalo Rollemberg Leite nasceu na cidade sergipana de Riachuelo em 14 de fevereiro de1906 e faleceu em Aracaju em 17 de julho de 1977. Bacharelou-se em Ciências Jurídicas e Sociais no ano de 1927 em Minas Gerais, passando a atuar como promotor de justiça. Professor, jornalista e jurista, fundou e por longos anos dirigiu a Faculdade de Direito de Sergipe, assumindo ali a cadeira de Direito Civil e consagrando-se como um dos mais respeitados professores daquela Faculdade. Diretor e redator de A República (BARRETO, 2002).
} 
fazer história $[\ldots] "$ ". Com esse pensamento analisamos o caderno de Maria Lígia Madureira Pina.

Entende-se o caderno "Como produto escolar, o caderno reflete a cultura própria do nível, etapa ou ciclo de ensino que é utilizado" (VIÑAO, 2008b, p. 25). O caderno aqui analisado não contém explicitamente uma data, mas foi guardado com cuidado por Maria Lígia Madureira Pina, aluna do curso entre os anos de 1955 a 1958. Trata-se de uma espécie de fichário que engloba folhas com anotações de diversas disciplinas e aparentemente das três séries finais do curso de Geografia e História da FCFS. No caderno, visualizam-se diferentes tipos de folhas, assim como três tipos de letras, com a preponderância de uma, além de várias folhas datilografadas. Em entrevista, Pina (2010) afirma que trabalhava durante todo o dia e estudava à noite, rotina que fazia com que algumas pessoas mais próximas "passassem a limpo" as suas anotações de aula, inclusive datilografando seus escritos.

O caderno com cento e noventa e duas páginas, quase todas com alguma marcação, contém uma capa dura marrom e anotações das seguintes disciplinas: História do Brasil, Sociologia da Educação, História da Civilização Moderna, História da Civilização Contemporânea e Didática Especial da História e da Geografia. Aqui analisamos os diferentes escritos que constam no caderno com foco na História da Civilização Moderna Contemporânea.

Em primeiro lugar consideramos necessário construir um perfil biográfico sintético desse professor, com o olhar voltado para sua atuação docente e mais especificamente como professor de História ${ }^{4}$. Assim, dedica-se um papel de

\footnotetext{
${ }^{4}$ Sobre Gonçalo Rollemberg Leite localizamos os seguintes trabalhos: Albuquerque (2005) situa-o na linhagem de Aurélia Dias Rollemberg, a Dona Sinhá; Azevedo (2002) escreve um pioneiro estudo sobre o jurista, com uma sucinta descrição de sua atuação; Barreto (2006) disserta acerca dos 100 anos desse Rollemberg Leite e percorre várias trilhas de sua vida; Nascimento (2007) traça um breve panorama da atuação do docente conclamando estudos que investiguem os silêncios produzidos acerca desta; Oliveira (2009) pesquisa a trajetória administrativa de Gonçalo Rollemberg Leite enquanto diretor da Faculdade de Direito de Sergipe no período de 1953 a 1970; a mesma autora, em outro trabalho, discorre sobre os seis fundadores da mencionada instituição, destacando entre eles Gonçalo Rollemberg Leite (OLIVEIRA, 2010). Os autores citados, exceto Azevedo (2002), registram em rápidas passagens a atuação de Gonçalo como professor de História no Atheneu Sergipense e em outras escolas do ensino secundário aracajuano, para além da Faculdade de Direito, instituição que contou com uma atuação mais efetiva de Gonçalo Rollemberg como professor e diretor. Nascimento (2007) destaca ainda a "predileção em escrever sobre História, intelectuais e cultura, de um modo geral" de Gonçalo Rollemberg Leite e Oliveira (2011) sublinha atuação do jurista como o professor de História da Civilização na FCFS, em meio a discussão sobre o ensino acadêmico de História em terras sergipanas.
} 
destaque para esse docente como importante agente dentro das disciplinas que compunham o eixo central do conhecimento histórico, logo depois trataremos das suas aulas por meio principalmente do caderno de uma discente e depoimentos dos seus alunos, buscamos assim elucidar qual a concepção de História do Professor Gonçalo e em seguida mostrarmos aspectos da sua prática de ensino.

\section{Traços da História do Professor Gonçalo Rollemberg}

Segundo Oliveira (2009), o jurista, além de ser filho de família abastada, cresceu em um ambiente de vários estímulos culturais e humanísticos, como também de disputas políticas das quais a família Leite constantemente fazia parte. Em Aracaju, estudou no Colégio Salesiano e no Atheneu Sergipense. Retornou para o Atheneu como catedrático de História da Civilização em 1938. Já no ensino superior atuou nas Faculdades de Ciências Econômicas, Direito, Serviço Social e na FCFS. Gonçalo Rollemberg Leite colaborou com jornais e revistas, além de diversas publicações ${ }^{5}$. Também integrou a Academia Sergipana de Letras, ocupando a Cadeira 23, na vaga do seu irmão Leite Neto no ano de 1967.

Todavia, sua atuação como professor de História é silenciada e ainda menos como professor de História na Faculdade de Filosofia de Sergipe. De fato, Gonçalo Rollemberg foi um dos seus fundadores e o responsável pelas cadeiras "XXIV - História da antiguidade e média" e "XXV - História moderna e contemporânea", que se subdividiam em disciplinas ministradas nos três primeiros anos do curso, além das aulas de Didática Especial da História no curso de Didática. Ou seja, as primeiras turmas de professores de História graduados em Sergipe contaram com os ensinamentos desse advogado durante os quatro anos de formação superior.

\footnotetext{
${ }^{5}$ Publicou, entre outros, A Árvore (Paraisópolis: Tipografia e Papelaria São José, 1928), Raças (Aracaju: Gráfica Editora, 1937), A Graça e a Reabilitação (Aracaju, 1942), Direito Civil (Aracaju: Livraria Regina, 1954), Contratos Imorais (Aracaju: Livraria Regina, 1959), João Ribeiro (Aracaju: Livraria Regina, 1962 - Separata da Revista da Faculdade Católica de Filosofia Ano 1, no 1, 1961), O Direito e as Letras (Aracaju: Livraria Regina, 1968 - discurso de posse na Academia Sergipana de Letras, 1967), Expressão Cultural de Sergipe (Aracaju: Livraria Regina, 1970 - Separata da Revista da Faculdade de Direito de Sergipe, 1967) (BARRETO, 2002).
} 
A preponderância de Gonçalo Rollemberg Leite nas disciplinas da História lembra o que Pierre Bourdieu denominou de capital simbólico, ou seja, "um crédito, é o poder atribuído àqueles que obtiveram reconhecimento suficiente para ter condição de impor o reconhecimento [...]" (BOURDIEU, 2004, p. 166). O capital simbólico do qual dispunha Gonçalo como professor de História do Atheneu Sergipense, entre outras atuações na sociedade sergipana, inclusive no magistério superior, somada a sua formação e pertencimento à elite econômica, conferiu-Ihe um crédito capaz de legitimar o seu reconhecimento como "O professor de História Geral", conforme o classifica Gonçalves (2010).

Gonçalo Rollemberg fez parte da geração de intelectuais sergipanos de meados do século $X X$, constantemente lembrado por seus traços de responsabilidade e exigência, marcados na instituição e nas disciplinas que ministrava. Seu ex-aluno Alexandre Felizola Diniz classifica-o como pertencente à ala dos professores formais do curso, e descreve sua postura:

Professor Gonçalo Rollembergue Leite, professor Gonçalo, extremamente formal. Ele entrava, dava bom dia, botava o cigarro na boca, ficava na frente, andando pra frente e pra trás e fumando, um, dois, três cigarros, acabava a aula ia embora, até logo e saía e pronto (DINIZ, entrevista ao autor, 2010). Dantas:

Essa fala de Diniz é endossada pela de sua colega de turma Beatriz Góis

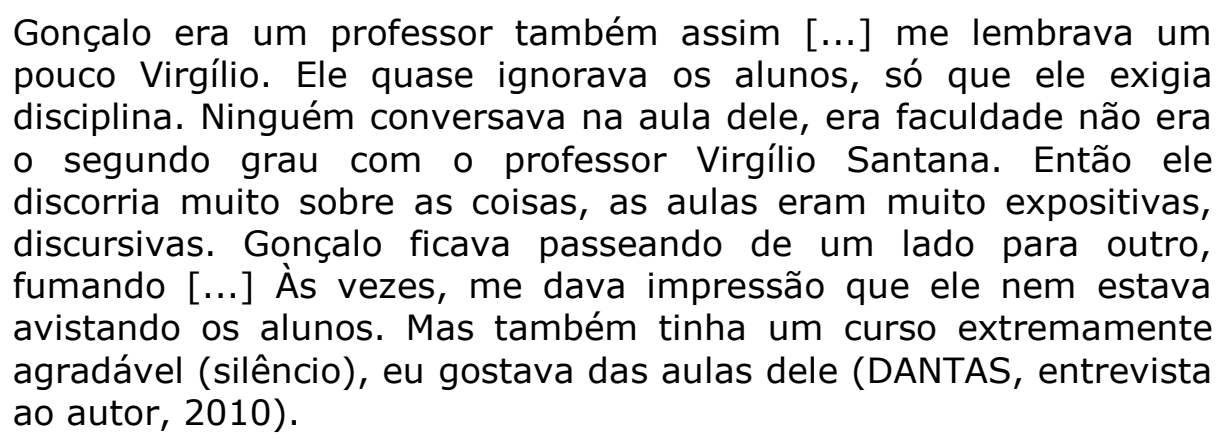

Pelos depoimentos, aliados a outras fontes, um sintético perfil do professor de História Gonçalo Rollemberg Leite seria de um docente formal, sério e exigente; e mesmo sentado em sua cadeira ou andando pela sala, fumava sem parar durante a exposição do assunto da aula, distante dos alunos no momento das preleções, mas exigindo o silêncio constante deles e o compromisso com as 
produções acadêmicas ${ }^{6}$. Usava o método expositivo para ministrar seus ensinamentos e era capaz de falar ininterruptamente sobre determinado assunto e mesmo assim prender a atenção da turma, composta quase exclusivamente por moças que copiavam o que o mestre dizia.

Mas o que pensava o jurista Gonçalo Rollemberg Leite acerca da História? Quais os autores lidos? Perguntas difíceis de responder, diante de um silêncio sobre sua atuação no âmbito do ensino de História. Entretanto, a tese apresentada no Atheneu Sergipense pode nos fornecer indícios, das influências teóricas do docente, como também da sua própria concepção de História.

\section{Gonçalo Rollemberg Leite: entre as concepções de História e sua prática de ensino}

A tese apresentada no concurso para Catedrático do Atheneu Sergipense datada de 1938 teve o título de Aspectos Econômicos da Idade Média. Com cento e vinte e cinco páginas, dividida em quatro tópicos: "Organização e economia feudais"; "Economia senhorial e urbana", "A indústria e a corporação", "O comércio e o capitalismo" - temas que também são subdivididos e acrescidos de conclusões e bibliografia -, a tese traz uma bibliografia ${ }^{7}$ majoritariamente

\footnotetext{
${ }^{6}$ Oliveira (2009) baseada em depoimentos orais, entre outras fontes, diz que entre os hábitos de Gonçalo Rollemberg Leite estava a compulsão pela leitura, o uso de tabaco e a exigência quanto à produção acadêmica.

7 Segue a transcrição da bibliografia da tese Aspectos Economicos da Idade Média (1938) de Gonçalo Rollemberg Leite: "CH. SEIGNOBOS - Histoire de la Civilisation au Moyen Age e dans les Temps Modernes; CH. SEIGNOBOS - Antiquité Romaine et Pré-Moyen Age; CH. SEIGNOBOS Histoire Moderne jusqu'en 1715; J. DE CROZALS - Histoire de la Civilisation; CESAR CANTÚ Histoire Universelle (tradução francesa); H. W. C. DAVIS - Europa Medieval (tradução espanhola); ANDRE MAUROIS - Historia da Inglaterra (tradução brasileira; EDWARD A. FREEMAN - General Sketch of European History; H. G. WELLS - The Outline of History; BASILIO DE MAGALHÃES - Historia do Comercio, Industria e Agricultura; ALCEU AMOROSO LIMA Introdução à Economia Moderna; ALCEU AMOROSO LIMA - Problema da Burguesia; WERNER SOMBART - La Industria (tradução espanhola; M. LAFFON-MONTELS - Les Etapes du Capitalisme de Hammourabi a Rockfeller; BARNES - History of Western Civilisation; PIERRE BRIZON Historie du travail et des travailleurs; CARLOS GIDE - Compendio d'Economia Política (tradução brasileira); EMILIO WILLEMS - Elementos de Historia Geral da Economia; MONTESQUIEU - De L'Esprit des Lois; HEODOR STERNBÉRG - Introducion A la Ciencia del Derecho (tradução espanhola); HENRI CAPITANT - Precis de Legislation Industrielle; RENÉ FOIGNET et EMILE DUPONT - Manuel de Legislation Industrielle; E. THALLER - Traité de Droit Commercial; JACQUES MARITAIN - Humanisme Integral; JONATHAS SERRANO - Philosophia do Direito; HUBERT LEY - L'artisanat entité corporative; VICOMTE GEORGE D'AVENEL - La Proprieté Fonciére de Philippe Auguste a Napoleon; VICOMTE GEORGE D'AVENEL - La Fortune Mobiliére
} 
francesa, com autores clássicos da História como Charles Seignobos, mas também com obras da área de Direito, Economia, Sociologia e Filosofia. Além dos brasileiros Alceu Amoroso Lima - com duas obras citadas - Basílio de Magalhães e Jonathas Serrano. Possivelmente alguns desses autores, outrora utilizados na sua tese, embasaram as aulas de Gonçalo Rollemberg na FCFS em meados do século $X X$.

Investigando como seriam as aulas de "História da Civilização" em outros locais do país, constata-se que na FFCL da USP esta disciplina também era "ministrada nos três anos do curso e se desdobrava em Antiga, Medieval, Moderna e Contemporânea, oferecidas por um único professor. Nela o professor deveria demonstrar todo o conteúdo do processo histórico mundial" (ROIZ, 2004, p. 74). Este autor esclarece ainda que Emile Cornaet foi o primeiro professor a ministrar a cadeira de "História da Civilização" na FFCL da USP, sendo substituído por Fernand Braudel no período de 1935 a 1937. A partir de 1938 ocorreu uma divisão "informal" dessa disciplina, entre Jean Gajé e seu assistente Eurípedes Simões de Paula.

Na Faculdade sergipana observamos um professor com uma formação e atuação na área do Direito, com mais de uma década de trabalho como professor de História na cobiçada congregação do Atheneu Sergipense, quando assumiu tais disciplinas na FCFS. Seus ex-alunos relatam aspectos marcantes da atuação do professor, Adelci Figueiredo Santos comenta:

[...] trabalhos eu me lembro como hoje que Gonçalinho me fez um trabalho que até hoje guardo sobre a memória das igrejas, é [...] das igrejas batista, adventista, presbiteriana, eu fiz um trabalho, eu fui em cada uma dessas igrejas fazer o levantamento sobre a história desse grupo. Até hoje eu guardo o trabalho, tirei dez com ele, e ele não era fácil de dar dez não, mas ele me deu e eu guardo esse trabalho com muito carinho (SANTOS, entrevista ao autor, 2010).

A fala da aluna chama atenção pela dificuldade de conseguir atingir as notas com o professor Gonçalo, além de alguns temas trabalhados na disciplina,

dans I'Histoire; VICOMTE GEORGE D'AVENEL - Le coût de l'a-meublement depuis sept siécles; VICOMTE GEORGE D'AVENEL - Les Acessoires de toilette; coiffures, armures et bijoux; EDMOND PLAUCHUT - Les Anciennes Provinces de la France-Le Berry; M. VICTOR DU BLED - La FrancheComté; M. ALFRED DE FOVILLE - La Population Française; A. DIEUDONNĖ - L'Actualité d'HierChanges et Monnaies au Moyen Age" (LEITE, 1938). 
que não figuram nos programas oficiais, nem mesmo nas cadernetas, como é o caso de um estudo sobre a memória das igrejas, ressaltamos também a maneira como a aluna faz referência ao professor "Gonçalinho", talvez a forma como aqueles alunos tratavam o sério Gonçalo Rollemberg Leite. Segundo descrição de Pina:

Doutor Gonçalo era um narrador por excelência. Bom timbre de voz, direto. Ele sentava lá na cadeira do professor, com um cigarro, emendava um cigarro no outro, fumava desbragadamente. Ele ficava com o cigarro até o toquinho. Mas contava a história e você tinha impressão de que estava assistindo ao fato. Era fabuloso! Às vezes se reclamava que era o mesmo método sempre, não sei mais o quê. Mas eu dizia, minha gente, doutor Gonçalo é o método, não precisa outro. O que ele explicava com aquela exposição, a gente ficava sabendo (PINA, entrevista ao autor, 2010).

As aulas seriam entremeadas pela narração do fato histórico como método, que já era questionado por alguns alunos e defendido por outros, pois ele "contava a história e você tinha impressão de que estava assistindo ao fato" e assim muitos alunos se encantavam pelas aulas do professor Gonçalo, como ficou destacado nas entrevistas efetuadas. Outros percebiam a necessidade de novos métodos para o ensino da História.

Outro elemento verificado, diz respeito à forma como as aulas eram ministradas; o professor sentado na cadeira dele e fumando, falando para os seus alunos, que anotavam o máximo que podiam de maneira rápida. Deste modo, possivelmente transcorriam as aulas sobre Egito, Grécia e Roma, entre outros temas do programa de ensino de História da Civilização Antiga e Medieval cujos conteúdos percorriam dos "prolegômenos" da História nas primeiras aulas do ano ao estudo de Roma, finalizando-as com o "julgamento de trabalhos" dos mais variados temas, realizados pelos discentes.

Para saber um pouco mais do que pensava Gonçalo Rollemberg Leite acerca desse período da história, explora-se sua já citada tese. Ali ele afirmava que o feudalismo iniciava com Luiz, o Pio, e só se encerrava com a Revolução Francesa, o que também ocorria na distribuição de pontos do seu programa de ensino de 1951 a 1962 na FCFS. O docente entendia que "o feudalismo naturalmente se tornaria motivo de opressão e obstáculo para o progresso" (LEITE, 1938, p. 118). E complementa: 
[...] regime social e político que dominou toda a Idade Média, e tirou o nome, das palavras germânicas fee, recompensa e od, propriedade, ou do vocábulo latino findes, o que parece mais provável, visto não se encontrar tal expressão na lei salica antes do século XI, e não possuí-la outros idiomas germânicos, a não ser o inglês que o recebeu do normando (LEITE, 1938, p. 04).

Mesmo com uma formação em Ciências Jurídicas e Sociais, Gonçalo Rollemberg Leite mostra domínio de conteúdo ao tratar do feudalismo, até mesmo porque a Idade Média foi o tema escolhido para sua tese. Esse foi possivelmente um dos períodos históricos que mais chamavam sua atenção, e para quem a Idade Média chegava até a Revolução Francesa, quando finalmente foram abolidos os privilégios angariados no período feudal. Entendendo o feudalismo como motivo de empecilho para o progresso, e como um regime não só político, mas também social, além de buscar a origem etimológica da palavra em questão, essa é a concepção de Gonçalo Rollemberg sobre a Idade Média em 1938.

Destarte, notamos como o professor entrevê esse período em que "[...] a Idade Média não foi um longo eclipse na história econômica da humanidade. 0 íato resultante da queda do Império Romano e da invasão dos bárbaros, atingiu, apenas a França e parte da Itália, e mesmo nestas regiões, se fez sentir tão só até o século XIII" (LEITE, 1938, p. 123). De modo que, uma das suas conclusões não se restringia a caracterizar a economia na Idade Média como um período de obscuridade, o candidato à cátedra de História da Civilização, relativiza a "escuridão" do feudalismo, afirmando que esse se limitou apenas a uma pequena parte da Europa e mesmo nesse espaço seu lastro temporal não chega até o século XVIII.

Pela análise das fontes percebemos que as ideias de Gonçalo Rollemberg expostas no citado trabalho podem ter contribuído para suas aulas de História da Civilização Moderna no curso de Geografia e História da FCFS, pois ali estava a base das suas concepções de História. Se esta apreciação estiver correta, os alunos do curso em foco aprendiam durante a graduação uma história medieval baseada nos aspectos políticos e econômicos, não a vislumbrando como "Idade das Trevas".

Tal afirmação baseia-se também na discordância explícita de Gonçalo Rollemberg Leite das ideias de Edward Gibbon - não citado na bibliografia da 
tese -, de que no "intervalo entre a cultura e organização romana e o Renascimento", ocorreu "uma longa noite de ignorancia e de violência" (LEITE, 1938, p. 124). O professor aderia ao pensamento de Henry William Charles Dawis na obra Europa Medieval, e citando este, afirmava que a Idade Média logrou feitos de profunda reflexão, frutos de uma sociedade civilizada. Este seria um dos seus entendimentos sobre a História, que possivelmente contribuiu para a formação dos professores de História do ensino secundário de tantas escolas sergipanas.

Outros aspectos podem ser sublinhados, como por exemplo, o ponto denominado "Civilização da Idade Média", que possivelmente tratava de espaços e costumes dos europeus com descrições pormenorizadas, característica do professor Gonçalo. Salientamos um de seus escritos sobre a vida na sociedade feudal.

\begin{abstract}
A vida social era a princípio simples e modesta. O mobiliário do castelo compunha-se de mesas e bancos de madeiras; camas estreitas forradas com palha; caixa de vime para guardar vestidos. Havia peças de ouro e prata de grade valor, porém, trabalhadas sem arte e sem gosto. [...] O vestuário ressentia-se da falta de roupa branca; os nobres usavam uma camisa de lã fina, de custo elevadíssimo. Os tecidos eram grosseiros. A arte e a indústria, visavam antes a guerra, então constante do que o conforto (LEITE, 1938, p. 30).
\end{abstract}

Essas exposições detalhadas abrangiam desde os móveis, utensílios até mesmo as roupas, além da constatação de que se trata de uma sociedade voltada para o mundo da guerra e não da comodidade. O zelo pela arte e pelo bom gosto também fica implícito no comentário do professor.

Cabe ressaltar ainda que na segunda série do curso de Geografia e História da FCFS o programa de ensino de História da Civilização Moderna estava descrito de forma a privilegiar um estudo eurocêntrico, concentrando suas análises num recorte temporal que historicamente foi construído como Idade Média e Idade Moderna. Notamos um ensino com foco nos "grandes Estados" da Europa, desde as suas organizações em diferentes Estados, até as suas revoluções e outros vários pontos que trabalhava especificamente com França, Alemanha, Inglaterra, Rússia e Prússia. 
Em meio ao estudo da igreja católica, as conversas de mulheres nos salões franceses do século XVIII e o entendimento de uma Idade Média que chegaria às "portas" da Revolução Francesa transcorriam as aulas de História da Civilização Moderna, ministradas com detalhes por um "viajante do tempo", defensor do papel da Igreja no feudalismo, contestador das ideias de Edward Gibbon e colaborador do pensamento Henry William Charles Dawis.

Já no tocante a História da Civilização Contemporânea, disciplina da terceira série do curso de Geografia e História, observa-se nas cadernetas de 1957 que no mês de março os assuntos foram a "Sociedade e a cultura no século XVIII" e "Economistas e filósofos do século XVIII". Já as oito aulas seguintes sobre "Revolução Francesa" não tinham maiores especificações.

Levando-se em consideração que o período de graduação de Maria Lígia Madureira Pina foi de 1955 a 1958, deduz-se que ela era aluna da terceira série de História da Civilização Contemporânea no ano de 1957. Ao analisarmos o caderno escolar dessa aluna, evidenciamos que as aulas começaram com um estudo sobre sociedade, cultura, economistas e filósofos do século XVIII (PINA, $\mathrm{s} / \mathrm{d})$, temas que teoricamente faziam parte do programa da segunda série do curso.

Segundo as anotações no caderno de Pina (s/d), a Europa no século XVIII estava dividida em três classes: nobreza, clero e povo, mas entre a nobreza e o povo surgiu uma nova classe: a burguesia, e depois desta vinham os artesãos filiados às corporações. Caracterizam-se também as vestimentas, casas e ruas de Paris do século XVIII e destacadamente as reuniões de nobres e intelectuais nas cortes, primeiramente nos "Cafés" e depois nos "Salões".

"Os salões tiveram muita importância na história da Europa e principalmente na França. As mulheres tiveram o ponto alto de sua vida, principalmente cultural. Estas regiões eram dirigidas por senhoras, as quais faziam questão de abrir os seus salões" (PINA, s/d). A partir dessa afirmação citam-se os nomes de várias mulheres, as quais Maria Lígia Madureira Pina (2010) menciona em entrevista ao ser questionada sobre as aulas de Gonçalo Rollemberg Leite, possivelmente depois de reler suas anotações e recordar algumas das tantas mulheres que inspiraram suas pesquisas, lembrando que a 
ex-aluno tinha sido avisada previamente sobre o tema da entrevista. Pina afirma:

Foi sobre a sociedade e a cultura no século XVIII, porque trata sobre a mulher. A mulher entrou muito nessa parte cultural, a abertura dos seus salões aos intelectuais, as mulheres já se sobressaiam. Da passagem do XVIII para o XIX surgiram mulheres magistrais como Madame de Geoffrin, Madame Duffont, Madame Roland, Madmoiselle Lespinasse. Essas mulheres influenciaram na abertura dos horizontes femininos. Veja que, não lembro se Madame Geoffrin ou Madame Duffont, uma das duas, era tão importante que foi quem indicou o nome de $D^{\prime}$ Alembert para a Academia. Eram mulheres extraordinárias. E depois surgiram as escritoras George Sand, Madame Stael [...] um grupo maravilhoso de mulheres que está registrado em 'A Mulher na História' (PINA, 2010).

Indubitavelmente, as aulas na década de 50 do século XX deixaram marcas naquela discente, pois as mulheres citadas, em meados de 1950, pelo professor Gonçalo Rollemberg Leite, possivelmente serviram de estímulo para as pesquisas da historiadora, professora de vários colégios aracajuanos e membro da Academia Sergipana de Letras, com uma vida dedicada ao estudo da história das mulheres.

Dentro dessa perspectiva, sublinhamos mais uma vez que os contornos de uma disciplina não se circunscrevem ao ambiente da sala de aula, pois pelo indício da fala da ex-aluna inferimos que a disciplina em foco conseguiu "moldar" determinadas concepções e interesses pela história. Como um exemplo disso, temos os vários trabalhos de Maria Lígia Madureira Pina com o foco na compreensão da história das mulheres. A entrevistada faz questão de mencionar as mulheres citadas naquela aula e que também constam em uma obra de sua autoria $^{8}$. Deste modo, o presente estudo também cumpriu as indicações de André Chervel (1990, p. 209) quanto a uma das tarefas do historiador das disciplinas, que é dar "conta da eficácia do ensino, e da transformação efetiva dos alunos", diante da aculturação sofrida por eles no ambiente escolar, apontando aqui como as disciplinas foram "eficazes" naquilo que estavam propondo.

Prosseguindo a análise do caderno de Pina (s/d) observa-se que ao tratar de "Economistas e filósofos do século XVIII", Gonçalo Rollemberg Leite dividiu a

\footnotetext{
${ }^{8}$ PINA, Maria Lígia Madureira. A mulher na história. s.l.: s.e., s.d.. 404 p.
} 
aula em cinco tópicos: "Financistas", "Letras", "Artes", "Música" e "Ciências". Sobre os financistas, afirmou que estes eram mal vistos na sociedade, pois seriam como ladrões; e citou Voltaire para fazer sua crítica. Voltaire também é um dos três filósofos mencionados na parte referente às "Letras", em conjunto com Montesquieu e Jean-Jaques Rousseau, descrevendo de forma sintética cada uma das obras de todos eles.

Cabe destacar a fala acerca da obra "O Espírito das Leis", de Montesquieu, como: "[...] o primeiro livro de Sociologia. Mostra que o homem muda de opinião, conforme o meio, o clima, a raça" (PINA, s/d, s/p.). Salientamos que esse livro consta na bibliografia da tese defendida por Gonçalo Rollemberg Leite em 1938. Este pode ser mais um vestígio de que as ideias dos autores utilizados pelo docente na década de 1930 ainda se faziam presentes nas suas aulas no curso de Geografia e História da FCFS.

No tocante ao estudo das "Artes", ressaltou o pintor Antoine Watteau com sua arquitetura de peças pequenas e as mobílias leves e de cor clara. Já na "Música" abordou J. S. Bach, Wilhelm Richard Wagner e Wolfgang Amadeus Mozart, e por fim "As Ciências", com o inglês Issac Newton e o francês René Descartes, além de uma série de inventores e suas proezas (PINA, s/d).

Além desses conteúdos, o caderno de Pina $(s / d)$ contém cinquenta e oito páginas com diferentes anotações acerca da Revolução Francesa e os seus desdobramentos, divididas em espécies de cinco "grandes aulas". Na ordem em que se localizam no caderno encontra-se: "A Convenção - Queda dos Girondinos - Ditadura Montanhesa"; "Obra Administrativa e Militar da Convenção Nacional"; "Ditadura de Robespierre"; "O Diretório" e "O Consulado". E ainda duas páginas com anotações sobre a "Restauração Francesa" e nove páginas desordenadas tratando da "Assembléia Legislativa" e a "Constituinte".

Pelo exposto no caderno citado, o professor trabalhava com espécies de "esquemas" do que seria visto no decorrer da aula, logo no início desta. Tomando como exemplo o assunto "A Convenção" foi assim tratado: "10 Abolição da Realeza; 20 Rivalidade entre girondinos e montanheses; 30 A execução do rei; 40 Queda dos Girondinos; $5^{\circ}$ Ditadura revolucionária; 60 Terra: levantamento, lei do máximo, descristianização, execuções" (PINA, s/d). Ou a "Ditadura de Robespierre" subdividida em "10 Robespierre e a política igualitária 
Hebert e Danton; 20 Ditadura de Robespierre: O Ser supremo, O G. Terror; 300 Termidor; 40 Transformação, Eliminação dos jacobinos, Renascimento Católico; $5^{\circ}$ Insurreição: jacobino, realistas" (PINA, s/d).

Depois da apresentação dos "esquemas" transcorriam as aulas. As anotações demonstram que Gonçalo Rollemberg procurava a todo o momento dar vivacidade à história contada, com diálogos constantes dos personagens. Segundo Santos (2010) "[...] era como se ele estivesse vivendo a História e a gente copiava". Algumas dessas passagens copiadas podem ser coletadas no caderno de Pina (s/d).

Ao tratar da "Convenção - Queda dos girondinos. Ditadura montanhesa" Gonçalo Rollemberg, aparentemente, fez uma breve introdução sobre o assunto e depois tratou do julgamento do rei da França. Segue "sua" descrição do fato, anotadas por uma aluna:

\begin{abstract}
A $1^{\text {a }}$ questão que deveria responder era a seguinte: 'É o rei culpado de conspirar contra a segurança nacional e as liberdades públicas?' Responderam sim por unanimidade; os que não quiseram dizer sim, se abstiveram de votar. A segunda pergunta foi 'o julgamento desta convenção deverá haver apelação para o povo?' A maioria respondeu que não'. 3a Questão: 'Deve ser imposta a pena de morte de Luís XVI da França?' Num total de 721 deputados, foi condenado por 53 votos de maioria. [...]. 4a Questão: 'Deve-se aplicar imediatamente a pena de morte ou retardar [...]' Responderam que se devia executar imediatamente e não esperar tempo nenhum. [...] Antes da execução um padre fez um pequeno discurso exclamando 'Um filho de S. Luís subirá ao céu'. Luís XVI falou ao povo, declarando que estava inocente; mas os tambores ruflaram e a guilhotina caiu (PINA, s/d).
\end{abstract}

Essa é uma história narrada com a descrição de fatos como se tivessem ocorrido exatamente dessa forma. Com sua fala segura e caráter sério, possivelmente provocava o convencimento daqueles futuros professores de História. Destaque também para o diálogo, com perguntas e respostas acerca da execução, a opinião da Igreja diante dos acontecimentos e o final da exposição digna de um espetáculo "os tambores ruflaram e a guilhotina caiu" (PINA, s/d).

E as narrações prosseguiam. Por exemplo, quando tratava do período do "Terror" na Revolução Francesa, descrevia a execução de "22 girondinos que caminharam para o patíbulo, cantando a Marselha". Entre os condenados estaria Mme. Rolland, que "Na hora da execução, olhando para a estátua da liberdade 
que se erguia ao lado exclamou: Liberdade, quantos crimes se comete em teu nome! Morreu com serenidade e firmeza" (PINA, s/d).

Cabe salientar a exaltação de uma figura feminina já citada em outra aula de História da Civilização Contemporânea, a qual possivelmente se tratava de uma mulher que marcou a formação de Gonçalo Rollemberg. As conclusões de suas aulas constantemente faziam exaltação àquele país. Ao concluir "Convenção" consta "Depois de tudo isto a França conseguiu vencer a Europa e a Revolução triunfou, o que não teria sido possível de outro modo". Já sobre o "Consulado" lê-se: "[...] conseguiu organizar tôda a França". E ao tratar de Napoleão Bonaparte: "Toda obra da Revolução foi destruída por Napoleão" (PINA, s/d).

Desse modo, transcorriam as análises da Revolução Francesa, com destacados personagens e suas falas, apóstrofes e exposições que denotam um docente com certo apego pela França. Segundo Oliveira (2009), a formação de Gonçalo Rollemberg Leite também perpassava a Economia, Política, Psicologia e Literatura Francesa, sendo a última cursada no Instituto Franco-Brasileiro de Alta Cultura. A autora também cita o depoimento de uma irmã do jurista, Clara Leite de Resende, falando sobre a formação humanista de Gonçalo, e afirma que a família contava com uma biblioteca no engenho da Fazenda Angico. Ou seja, desde a infância a sua formação literária contou "[...] com uma seleção cuidadosa de obras dos clássicos e revistas, como as ilustrações francesas, noticiando os acontecimentos que ocorriam na Europa e no mundo" (RESENDE, apud OLIVEIRA, 2009c, s/p).

Tais leituras efetuadas na infância, aliadas a um curso de literatura francesa e à sua formação no ensino superior contribuíram para as diferentes aulas de História da Civilização ministradas no curso em foco. Além disso, podem explicar, em certa medida, como o professor conseguia fazer tantas descrições pormenorizadas de fatos e personagens de determinados momentos históricos. 


\section{Considerações finais}

Aqui tratamos de um curso de formação de professores de História, e mesmo Gonçalo Rollemberg Leite não possuindo formação na área, como era o caso de Maria Thétis Nunes também professora do curso, foi seu nome que ficou guardado na memória dos seus ex-alunos como o pilar das disciplinas da História. Sem dúvida, o montante de capital simbólico que ele conseguiu angariar impôs o seu reconhecimento.

A partir da análise das três disciplinas ministradas por Gonçalo Rollemberg Leite inferimos que as aulas deixaram lembranças nos seus discentes e certamente influenciaram no entendimento dos aspectos relacionados à História ali discutida, desde as suas divisões cronológicas e assuntos, como a postura do professor e sua maneira de narrar os acontecimentos. Isto porque, conforme Dantas (2010), Gonçalo era um homem culto e muito interessado em assuntos como a cultura e arte em geral, temas que ele descrevia por meio de detalhes de países, monumentos, personagens, batalhas e lugares que foram palcos de determinados fatos históricos. Nas palavras de Adelci Figueiredo Santos (2010), a aula de Gonçalo Rollemberg Leite:

Era magistral, ele passeava durante todo o tempo [...] ele era sisudo, mas uma pessoa do coração grande, muito bem formado, inteligentíssimo e de uma memória impressionante, impressionante, ele falava durante cinqüenta minutos ininterruptamente e ninguém cansava, as aulas dele eram assim (SANTOS, entrevista ao autor, 2010).

Aulas pouco dialogadas com uma fala constante e que impressionava os alunos; e apesar de sério, conseguia ao menos conquistar o carisma dos seus discentes. Contudo, sem sombra de dúvidas, algo que também marcou a história ministrada pelo professor Gonçalo Rollembergue Leite era o fato de ele fumar sem parar, um cigarro após o outro, durante toda a aula. Este fato foi mencionado e ressaltado por todos os ex-alunos entrevistados, e embora não conste nos documentos oficiais, certamente "entre nuvens de fumaça" transcorriam as aulas da chamada "História da Civilização", tripartida em "Antiga e Medieval", "Moderna" e "Contemporânea". 
Gonçalo Rollemberg Leite não limitou a sua visão da história à escrita de Aspectos Econômicos da Idade Média em 1938, mas contribuiu sobremaneira para formação de professores de História que frequentaram os bancos do curso de Geografia e História da FCFS em meados do século XX e assim podemos concluir que vários elementos do entendimento de Gonçalo Rollemberg Leite acerca de conteúdos da História esboçados na sua tese escrita em 1938 para um concurso na cobiçada congregação do Atheneu Sergipense se fizeram presentes na sua prática de ensino nas salas de aula da Faculdade Católica de Filosofia de Sergipe, sendo que a sua concepção do que seria Idade Média, ou outros tantos assuntos ali ensinados não só formaram diferentes professores do ensino secundário e normal de Sergipe, mas pode ter influenciado nas aulas desses docentes e se espalhado por diferentes espaços educacionais em diferentes lugares.

Pensando dentro dessa perspectiva as aulas de Gonçalo Rollemberg Leite tem muito a nos dizer sobre o ensino de História em Sergipe e fica a certeza de que várias são as faces do ensino acadêmico de História que ainda precisam ser desveladas. Aqui tomamos como base um caderno, uma tese e alguns depoimentos de ex-aluno para analisarmos o ensino de História da Civilização na Faculdade Católica de Filosofia de Sergipe, uma entre tantas histórias que um professor, uma disciplina e alguns alunos têm a nos mostrar sobre um recorte do passado educacional de um grupo.

\section{Referências}

AlBuquerque, S. B. de M. Memórias de Dona Sinhá. Aracaju: Typografia Editorial/ Sccorttecci Editora, 2005.

AZEVEDO, C. B. de. Gonçalo Rollemberg Leite e a direção da Faculdade de Direito de 53 a 70. Jornal CINFORM. Edição 991.08 a 14 de abril. 08 a 14 de abril. Caderno de Cultura, p. 53. Aracaju-SE, 2002.

BARReTO, L. A. Pequeno dicionário prático de nomes e denominações de Aracaju. Aracaju: ITBEC/ BANESE, 2002.

BARRETO, L. A. Os 100 anos de Gonçalo Rollemberg Leite. Disponível em <http://www.infonet.com.br/luisantoniobarreto/ler.asp?id=44237\&titulo=Luis A ntonio Barreto ${ }^{>}$Publicado em 16 de fevereiro de 2006 . Acesso em 16 de dezembro de 2010. 
BOURDIEU, P. O campo intelectual: um mundo à parte. In: . Coisas ditas.

São Paulo: Brasiliense, 2004. p. 169-180

Os usos sociais da ciência: por uma sociologia clínica do campo científico. São Paulo: Editora da UNESP, 2004.

CERTEAU, M. de. A Escrita da História. 2. ed., Rio de Janeiro: Forense, 2008.

CHERVEL, A. História das disciplinas escolares: reflexões sobre um campo de pesquisa. Teoria \& Educação, n. 2, 1990, p. 177-229.

LEITE, G. R. Aspectos econômicos da Idade Média. Tese apresentada ao Atheneu Sergipense para o concurso de catedrático de História da Civilização. Aracaju: Casa Ávila Tipografia e Papelaria, 1938.

NASCIMENTO, J. C. do. Silêncios e esquecimentos da história da educação em Sergipe: o professor Gonçalo Rollemberg Leite. Publicado em 28 de janeiro de 2007. Disponível em: <http://jorge.carvalho.zip.net/arch2007-01-28_2007-0203.html> Acesso em: 16 de dezembro de 2010.

OLIVEIRA, M. T. J. A trajetória administrativa de Gonçalo Rollemberg Leite junto à Faculdade de Direito de Sergipe (1953 - 1970). Anais do IX Congresso Iberoamericano de História da Educação Latino-Americana. Rio de Janeiro - RJ. 2009.

. Elites, Intelectuais e Docência: anotações prosopográficas de professores fundadores da Faculdade de Direito de Sergipe. Anais do VIII Congresso Luso-Brasileiro de História da Educação: Infância, Juventude e Relações de Gêneo na História da Educação. 2010.

OLIVEIRA, J. P. G. Disciplinas, docentes e conteúdos: itinerários da História na Faculdade Católica de Filosofia de Sergipe (1951-1962). Dissertação (Mestrado em Educação). Núcleo de Pós-Graduação em Educação da Universidade Federal de Sergipe. São Cristóvão, Sergipe, 2011.

PINA, Maria Lígia Madureira. Caderno. s/d. A mulher na história. s.l.: s.e., s.d.. 404 p.

ROIZ, D. da S. A institucionalização do ensino universitário de História na Faculdade de Filosofia, Ciências e Letras da Universidade de São Paulo. 19341956. Dissertação (Mestrado em História). Faculdade de Ciências Humanas e Sociais da Universidade Estadual Paulista "Júlio de Mesquita Filho". Franca, São Paulo, 2004.

VIÑAO, A. A história das disciplinas escolares. Trad. Marina Fernandes Braga. Revista Brasileira de História da Educação. n. 18, set/dez. 2008a. p. 173-214.

Os cadernos escolares como fonte histórica: aspectos metodológicos e historiográficos. In: MIGNOT, A. C. V. (Org.). Cadernos à vista: escola, memória e cultura escrita. Rio de Janeiro: EdUERJ, 2008b. p. 15-33. 


\section{Fontes Orais}

DANTAS, Beatriz Góis Dantas. Ex-aluna do curso de Geografia e História da FCFS. Entrevista concedida ao autor em 3 de Junho de 2010. Aracaju-SE.

DINIZ, José Alexandre Felizola. Ex-aluno do curso de Geografia e História da FCFS. Entrevista concedida ao autor em 10 de Junho de 2010. Aracaju-SE.

GONÇALVES, Maria de Matos. Ex-aluna do curso de Geografia e História da FCFS. Entrevista concedida ao autor em 29 de maio de 2010. Aracaju-SE.

SANTOS, Adelci Figueiredo. Ex-aluna do curso de Geografia e História da FCFS. Entrevista concedida ao autor em 10 de Junho de 2010. Aracaju-SE.

PINA, Maria Lígia Madureira. Ex-aluna do curso de Geografia e História da FCFS. Entrevista concedida ao autor em 08 de Junho de 2010. Aracaju-SE.

Recebido dia 05 de fevereiro de 2013. Aprovado em 08 de agosto de 2013. 